\title{
Prevalence study on Vulvar neoplasia in Navarre from 2007 to 2015
}

\begin{abstract}
Vulvar cancer is a rare disease both in Spain and in the rest of the world. The incidence ranges from 0.5 to 3 cases per 100,000 women per year. The common symptom of vulvar cancer is a permanent itching. Vulvar surgery research has found that complications such as comorbidity, humidity, dehiscence and infections are among the most frequent reasons for delaying hospital discharges. This is a retrospective, descriptive study based on computerized medical records from the Gynecologic Oncology Department at the Navarre Hospital Center (Spain), a tertiary level hospital. Sample obtained $(\mathrm{n}=62)$ with a percentage of $75.8 \%$ of squamous tumors.
\end{abstract}

Keywords: vulva, cancer, morbidity, dehiscence, infection

\author{
Volume 3 Issue 3 - 2017
}

\author{
Gonzalo Esparza Imas,' Maria Pilar Borruel \\ Sola, ${ }^{2}$ Maria Teresa Gonzalez Gomez, ${ }^{3}$ \\ Cristina Labarga Etulain ${ }^{3}$ \\ 'Nurse, Unit Nursing Pool and Coordination Heads of Guard, \\ Hospital Complex of Navarre, Spain \\ ${ }^{2} \mathrm{Head}$ of Maternal Nursing Unit, Hospital Complex of Navarre, \\ Spain \\ ${ }^{3}$ Department of Gynecological Pathology, Surgery and Oncology, \\ Hospital Complex of Navarre, Spain
}

\begin{abstract}
Correspondence: Gonzalo Esparza Imas, Nurse, Unit Nursing Pool and Coordination Heads of Guard, Hospital Complex of Navarre, Spain, Tel 003463657 0250,
\end{abstract}

Email gonzalo.esparza.imas@navarra.es

Received: June 02, 2017| Published: July II, 2017

\section{Introduction}

Vulvar cancer is a rare disease in both Spain and the rest of the world. Its incidence ranges from 0.5 to 3 cases per 100,000 women per year. Morbidity in vulvar surgery at the gynecological oncology surgery department--Gynecologic Oncology Department at the Navarre Hospital Center (Spain)--meets the criteria defined in the data published in different studies ${ }^{1,2}$ which aggravate, difficult and complicate the evolution of a complex pathology itself. It is estimated that worldwide, in 2002, 28,600 new cases were diagnosed representing an incidence of 1.5 cases per 100,000 women per year.

Under the category "vulvar cancer" different tumors are included depending on the tissue in which these tumors originate. Squamous or epidermoid cancer, originated in the skin covering the above mentioned organ, is the most common and accounts approximately for $85 \%$ of all vulvar neoplasm's. The rest of them, in order of frequency are: melanoma, sarcoma, adenocarcinoma and other rarer types. Malignant vulvar tumors account for $4 \%$ to $5 \%$ of all gynecological cancers. Only vaginal cancer is even less frequent among gynecological cancers. In recent years, most tumor records describe an increased incidence in vulvar cancer, and especially precancerous lesions in both young (relative to the higher prevalence of infection by the human papillomavirus (HPV)) and older women.

Most women with vulvar cancer are postmenopausal and over 60 years of age, although cases are increasingly occurring in young women. The distribution curve by age is bimodal with two peaks of higher incidence: young women (40 years of age average) and older women (60-70 years of age average). ${ }^{3}$ This data are explained because squamous vulvar cancer, representing $90 \%$ of these neoplasm's, include two different types of disease, both from the clinical epidemiological and the etiological points of view. These are:

i. The viral cancer type caused by oncogenic types of HPV, ${ }^{4}$ which is diagnosed in young women with sexual risk factors and smoking habits, and is usually preceded by precursor lesions (VIN) approximately ten years in advance.

ii. Squamous vulvar cancer unrelated to HPV, which affects elderly women and is usually preceded by no neoplastic skin diseases (lichen sclerosus and squamous cell hyperplasia).

iii. Vulvar cancer in young women, HPV related, is frequently diagnosed in an early stage or its precursor stage (VIN). Cancer in older women, despite vulvar lesions associated with dystrophic lesions with many years of evolution, is the most frequently diagnosed in advanced stages. Overall, more than one third of patients, at diagnosis, have tumors smaller than $2 \mathrm{~cm}$. or at precursor stage, and more than two thirds show lesions limited to the vulva or perineum regardless of size. The common symptom of vulvar cancer is a permanent itching.

\section{Vulvar cancer distinctive symptoms}

Other very distinctive symptoms of this condition include:

i. Long term itching on the vulva. Usually nonspecific and can occur under various conditions. It is not usually a symptom of vulvar cancer diagnosis.

ii. Some women may develop a lump or swelling of the vulva. This is usually on or near the vaginal lips.

iii. There may be pain and discomfort in the vulva especially when urinating or during sex.

iv. There may be inflamed, red or white, or blackened skin areas.

v. There may be bleeding unrelated to menstruation from the vulva or the vagina.

vi. There may be a spur or a wart on the vulva, which recently changed its shape, size or color.

vii. Some women may develop lesions and ulcers with pain on the vulva that persist more than a month. 
viii. The lesion in advanced stages can affect nearby lymph nodes. These lymph nodes may appear swollen and show rubber consistency.

Vulvar surgery research has found that complications such as comorbidity, humidity, dehiscence and infections are among the most frequent causes of delay in hospital discharges. ${ }^{5}$ Skin moisture, caused by incisional and perilesional edema along with the involvement of lymphatic drainage after unilateral or bilateral lymphadenectomies, ${ }^{6-8}$ increases incisional dehiscence and surgical area infection. This is due largely to the anatomical conformation where surgical approaches occurred. ${ }^{7}$ Suture dehiscence caused by exudates is, together with moisture, one of the prevalent complications in vulvar surgical procedures. ${ }^{7,9,10}$ Infection ${ }^{11}$ as process of increased complexity and difficulty in the healing process ${ }^{12,13}$ extends the caring processes in both therapeutic and rehabilitative cutaneous approaches, prolonging average hospital stays and use of both human and material resources.

\section{Objectives}

Main: Analyze the prevalence of vulvar cancer in Navarre.

Secondary: Evaluate the morbidity in vulvar cancer post-surgery.

\section{Methodology}

This is a retrospective, descriptive study based on computerized medical records from the Gynecologic Oncology department at the Navarre Hospital Center (Spain), a tertiary level hospital. This study includes the total population of patients treated of vulvar neoplasms between 2007 and 2015 at the gynecologic oncology department, on the 3rd Floor Maternal section at the Navarre Hospital Center.

\section{Study variables}

Age, diagnosis, staying days, diabetes, obesity, dermatitis, dehiscence and surgical wound infection.

\section{Results}

A sample of $n=62$ is obtained in the period from 2007 to 2015 , being the average 78 years of age. (Range $=44$ years of age; lower cap 56 years old, upper cap 100 years old) Table 1 . Female average population older than 20 years of age, between 2007 and 2015, is 245,063, being 2010 the highest incidence with 11 cases. The arithmetic mean of cases/year is 6.88 , being the prevalence of vulvar cancer in Navarre of 2.80 per 100,000 women. Vulvar cancer diagnostics are grouped into different types of tumors, being the new lump squamous cells the most significant diagnosis with $75.8 \%$ of the total sample; $21 \%$ diagnosis associated with lichen, and $8.1 \%$ linked to HPV/VIN Table 2 . The average patient stay is 11 days; 3 days average for patients with bed immobility rest; and 6 days average for patients using a urinary catheter after surgery. Patients undergoing surgery are $67.41 \mathrm{~kg}$ heavy and $151.71 \mathrm{~cm}$ tall average, with a BMI of 28.3(overweight). Out of these patients, $16.1 \%$ of the samples are diabetic: 7 patients $(11.3 \%)$ DMI and 3 patients (4.8\%) DMII. Dry surgical healing (applying povidone iodine and a gauze) represents $38.7 \%$ of the intervened patients. There is no dry healing type records (dry vs. wet) in $61.3 \%$ of the cases described. Peri-incisional skin dermatitis was diagnosed in 9 cases (14.5\%); it did not show in 36 cases (58.1) and it was not recorded, neither as affirmative nor negative, in 17 of the cases (27.4\%). Dehiscence suture vulva occurred in 16 cases $(25.8 \%)$, being the left and/or right lymphadenectomy dehiscence in a fewer number of cases, 8 of them $(12.9 \%)$.
Table I Distribution of samples according to age range

\begin{tabular}{ll}
\hline Age range & Sample \\
\hline $50-59$ years & 12 \\
$60-69$ & 8 \\
$70-79$ & 17 \\
$80-89$ & 16 \\
$90-99$ & 8 \\
$>100$ & 1
\end{tabular}

Table 2 Distribution of vulvar cancer diagnoses.

\begin{tabular}{lll}
\hline Diagnostics & N. cases & Percentage \\
\hline Squamous & 47 & $75,8 \%$ \\
Basocellular & 3 & $4,8 \%$ \\
Epidermoid & 3 & $4,8 \%$ \\
Melanoma & 3 & $4,8 \%$ \\
Wart Tumor & $\mathrm{I}$ & $1,6 \%$ \\
Minor vulvar lip tumor & $\mathrm{I}$ & $1,6 \%$ \\
Paget'S disease & 3 & $4,8 \%$ \\
\hline
\end{tabular}

\section{Discussion and conclusion}

\section{Data compared to national and international studies}

This retrospective study shows that the incidence of vulvar cancer in Navarre, 2.8 per 100,000 women/ year, is within the worldwide vulvar cancer incidence range, 0.5 and 3 per 100,000 women. It is comparatively higher than the incidence in the US and Europe (1.7 per 100,000). The incidence of vulvar cancer in Navarre is similar to that of Spain 2.7 per 100,000 women. ${ }^{14}$

Considering age groups, in Navarre, it can be observed an increase in cases in 50-59 year olds and in 70-89 year olds as it happens in the US, being the ages 75-84 the ages with the highest incidence. Although these data are similar, there is a difference regarding the average age, being 78 in Navarre and 68 in the US. This may be because the study periods are not the same, and the trend in the incidence of vulvar cancer is to be increasing in the future. Statistical models have predicted that the average increase in cases will be $0.6 \%$ annually over the next 10 years in the US.

\section{Peak incidence year}

2010 was the peak incidence year of vulvar cancer surgery in Navarre (11 cases), reaching a rate of 4.49 per 100,000 women. The range in the affected women ( 30 years: $59-89$ year olds) diversifies the sample without providing a causal or a binding relationship.

\section{Comorbidities (diabetes, obesity, dehiscence, infection)}

Pre-surgery conditions such as diabetes, obesity, age, and late diagnosis (patients visiting a specialist when the lesion has reached advanced stages) are factors that increase risks. The most common short term post-surgery complications (dehiscence, edema, and maceration, type of surgery used and/or infection of the surgical wound) are factors that prolong the care processes and increase the complications in perineal surgery. Surgical technique choice, poor accessibility in many cases to the area to treat, and the type of healing 
chosen are factors that predispose to increased hospital stay and must be taken into account. In the long run, lower limb lymphedema is the most common complication in connection with motor deficits or disabling deficits that increase the lymphatic cluster in affected areas with limited drainage. This aspect, along with the recurrence should be enough reason for an overall and derivable monitoring by the different healthcare levels.

\section{HPV, cervical and vulvar cancer among the immunized population}

HPV subgroup primary prevention associated with vulvar carcinoma and its precursor lesions is focused on preventing genital HPV infections. Since there is a binding relationship between HPV and the development in later stages of vulvar carcinoma, early age immunization is presented as critical recommendation. It have been observed a significant relationship between HPV infection and the development of vulvar carcinoma. ${ }^{15}$ Immunization is recommended for all 9-14 years old girls according to the Navarre Regional Foral Order 349/2015 on December 21 issued by the Health Secretary for which adult immunization schedule is established in Navarre. It is the main primary prevention of injuries associated with VIN Figure 1. Immunization is recommended for all young women reaching the age of 15 who have not been previously immunized. ${ }^{16}$

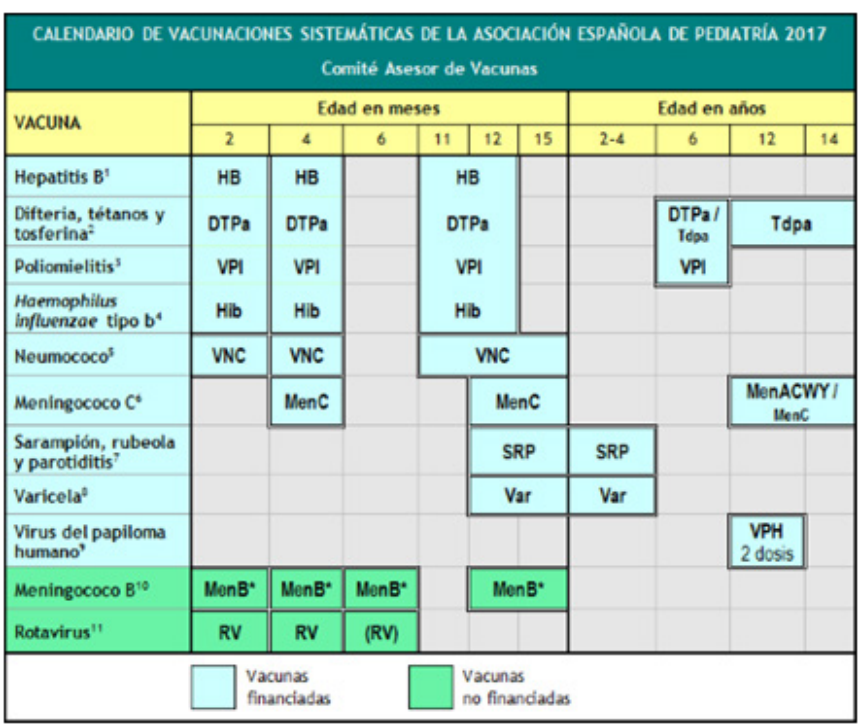

Figure I AEP 2017 immunization schedule in navarre (spain).

Secondary prevention is equally important and necessary: ${ }^{17,18}$

i. Check-up and exploration of the entire vulva, as part of gynecological cancer screening.

ii. Early diagnosis of vulvar carcinoma. Evaluation and study of early symptoms as well as their precursor lesions. These are often nonspecific or absent.

iii. Resistant treatment that persists for several weeks should be treated and assessed in detail.

\section{iv. Clinical examination}

If vulvar cancer is suspected, diagnosis based on clinical development:

i. Inspection of the vulvar area with colposcopy and vulvoscopy. Preparation of the area, including groin area and rectum. ii. Biopsy of suspected areas

iii. Methods to identify carcinomas and precancerous lesions: Clinical examination (exploration, palpation) and vulvoscopy applying acetic acid.

Clinical records remain one of the pending issues for the health disciplines, being the lack of records a continuous trend both in Medicine and Nursing, where variability in recording methodology is wide. The prevalence of vulvar cancer in Navarre is similar to that established by various national and international studies. Post-surgery morbidity is one of the modifiable factors in reducing hospital stay and improves quality of care in patients after surgery. The trend to use more conservative surgical techniques reduces hospital stay without changing relapse or survival rates. Preventing HPV will be analyzed in coming decades and studies on vulvar and associated cancers, assessing the effectiveness of mandatory vaccination according to a immunization schedule.

\section{Acknowledgements}

None.

\section{Conflict of interests}

The authors of this study declare not to have any type of conflict of interest in conducting this study.

\section{References}

1. Pablos JMS, Diego OB, de Oro OAV, et al. Estrategia terapeútica del cáncer de vulva en el instituto nacional de oncología y radiobiología. Rev Cubana Oncol. 2001;17(2):138-144.

2. Esperón Noa RP, Valdés Jiménez JM, Montero León JF, et al. Exenteración pélvica en el cáncer avanzado de la vulva. Presentación de caso. Revista Habanera de Ciencias Médicas. 2013;12(4).

3. Muñoz G, Robles F, Solorza L, et al. Morbilidad y recurrencia de la disección inguino-femoral con incisión limitada en carcinoma epidermoide de vulva. Rev Inst Nal Cancerol. 2000;46(3):171-174.

4. Messing MJ, Gallup DG. Carcinoma of the vulva in young women Obstet Gynecol. 1995;86(1):51-54.

5. Minari C, Guerreiro J. Cancer de Vulva: estudo restrospectivo das pacientes tratadas com vulvectomia radical. Rev Bras Oncologia Clínica. 2009;6(16):12-15.

6. Van der Zee AG, Oonk MH, De Hullu JA, et al. Sentinel node dissection is safe in the treatment of early-stage vulvar cancer. J Clin Oncol. 2008;26(6):884-889

7. Úbeda MVB. Dehiscencia de herida quirúrgica tras resección de melanoma vulvar. Enfermería Dermatológica. 2012;6(17):41-43.

8. Vidal Sicart S, Doménech B, Luján B, et al. Ganglio centinela en cánceres ginecológicos. Nuestra experiencia. Revista Española de Medicina Nuclear. 2009;28(5):221-228.

9. Blanco-Benavides R, Zárate-Castillo J. Factores de riesgo para dehiscencia de herida quirúrgica. Cir Ciruj. 2000;68:198-203.

10. Galindo Ortega L. Dehiscencia de herida quirúrgica en la paciente gineco-obstetrica; 1996.

11. Pujol M, Limón E. Epidemiología general de las infecciones nosocomiales. Sistemas y programas de vigilancia. Enfermedades Infecciosas y Microbiología Clínica. 2013;31(2):108-113.

12. Folch L, García M, Sánchez E. Conocimientos de las enfermeras sobre los cuidados de la zona de incisión quirúrgica en el postoperatorio. Enfermería Clínica. 2002;12(2):65-69. 
13. Asensio Á, Cantón R, Vaqué J, et al. Etiología de las infecciones hospitalarias en España (EPINE, 1990-1999). Medicina clínica. 2002;118(19):725-730.

14. Gil-Prieto R, Cortés J, Manuel Ramón y Cajal J, et al. Hospitalization in Spain associated with malignant neoplasias of the vulva and vagina (1997-2008). Hum Vaccin. 2011;7(8):856-863.

15. De Vuyst H, Clifford GM, Nascimento MC, Prevalence and type distribution of human papillomavirus in carcinoma and intraepithelial neoplasia of the vulva, vagina and anus: A meta-analysis. Int J Cancer. 2009;124(7):1626-1636.
16. Bermúdez JM. Vacunación frente al virus del papiloma humano y adolescencia. PediatríaIntegral. 2015;10(6):693:682.

17. Schnürch H, Ackermann S, Alt C, et al. Diagnosis, Therapy and followup care of vulvar cancer and its precursors. guideline of the DGGG and DKG (S2k-Level, AWMF Registry Number 015/059, November 2015. Geburtshilfe und Frauenheilkunde. 2016;76(10):1035-1049.

18. Maclean AB. Vulval cancer: prevention and screening. Best Practice \& Research Clinical Obstetrics \& Gynaecology. 2006;20(2):379-395. 